\begin{tabular}{lll}
\hline ISSN: 1410-8917 & Jurnal Kimia Sains dan Aplikasi 21 (1) (2018):44-48 \\
\hline Jurnal Kimia & Jurnal Kimia Sains dan Aplikasi \\
Apaiks \& & Journal of Scientific and Applied Chemistry & \\
e-ISSN: $2597-9914$ & Journal homepage: $\underline{\text { Attp://ejournal.undip.ac.id/index.php/ksa }}$ \\
\hline
\end{tabular}

\title{
Synthesis and Antibacterial Testing of Imina Derivative Compounds from Piperonal and Anilin
}

\author{
Dimas Syamsudin ${ }^{\mathrm{a}}$, Ismiyarto ${ }^{\mathrm{a}^{*}}$, Ngadiwiyana $^{\mathrm{a}}$ \\ a Organic Chemistry Laboratory, Chemistry Department, Faculty of Sciences and Mathematics, Diponegoro University, Jalan Prof. \\ Soedarto, Tembalang, Semarang \\ * Corresponding author: ismiyarto@live.undip.ac.id
}

Article Info

Keywords:

synthesis, imine, piperonal, aniline, antibacterial

\section{Abstract}

Synthesis of Imine derivates used as antibacterial activity has been done. Synthesis was conducted by condensation reaction between piperonal and aniline. The product synthesis was characterized by melting point, LC-MS, FTIR and ${ }^{1} \mathrm{H}-\mathrm{NMR}$, then application of the product as antibacterial towards bacteria Staphylococcus aureus and Escherichia coli. The product of synthesis was pale-brown solid, and had melting point at 56-61 ${ }^{\circ} \mathrm{C}$. Identification by LC-MS showed the compound molecular weight was 225.30 gram/mol, identification by FTIR showed a compound contained imine $\mathrm{C}=\mathrm{N}$ at 1620.21 $\mathrm{cm}^{-1}, \mathrm{C}-\mathrm{H}$ aromatic at $1581.63 \mathrm{~cm}^{-1}, \mathrm{C}_{\mathrm{sp} 3}-\mathrm{H}$ at $2962.37 \mathrm{~cm}^{-1}$ from $\mathrm{CH}_{2}$, and $\mathrm{C}-\mathrm{O}$ at 1265.30 $\mathrm{cm}^{-1}$, Identification by ${ }^{1} \mathrm{H}-\mathrm{NMR}$ showed a compound had a singlet peak at $\delta=6 \mathrm{ppm}$ that proton was from the $\mathrm{CH}_{2}$, multiplet peak at $\delta=6.9-7.7 \mathrm{ppm}$ proton from two aromatics and singlet peak at $\delta=8.4 \mathrm{ppm}$ from proton imine. The minimum inhibitory concentration of the product towards Staphylococcus aureus and Escherichia coli was 1 $\mathrm{mg} / \mathrm{mL}$ with diameter inhibition zone $2 \mathrm{~mm}$ and $3 \mathrm{~mm}$. From these data it could be concluded that the compound 3,4- methlenedioxybenzilyimine was formed and it had ability as an antibacterial agent.

Abstrak

Telah dilakukan penelitian tentang sintesis dan uji antibakteri senyawa turunan imina. Sintesis dilakukan melalui reaksi kondensasi antara piperonal dan anilin. Hasil sintesis dikarakterisasi dengan uji titik leleh, LCMS, spektroskopi FTIR dan ${ }^{1} \mathrm{H}-\mathrm{NMR}$, hasil sintesis diaplikasikan sebagai antibakteri terhadap bakteri Staphylococcus aureus dan Escherichia coli. Hasil sintesis berbentuk padatan, berwarna coklat pucat dan mempunyai titik leleh $56-61^{\circ} \mathrm{C}$. Identifikasi menggunakan LC-MS menunjukkan bahwa senyawa mempunyai berat molekul 225,30 gram/mol, identifikasi menggunakan FTIR menunjukkan bahwa senyawa hasil sintesis mengandung gugus fungsi imina $\mathrm{C}=\mathrm{N}$ pada bilangan gelombang $1620,21 \mathrm{~cm}^{-1}$, serapan $\mathrm{C}-\mathrm{H}$ aromatik pada bilangan gelombang $1581,63 \mathrm{~cm}^{-1}$, serapan pada bilangan gelombang $2962,37 \mathrm{~cm}^{-1}$ menunjukkan vibrasi $\mathrm{C}_{\mathrm{sp} 3}-$ $\mathrm{H}$ dari $\mathrm{CH}_{2}$ dan serapan $\mathrm{C}-\mathrm{O}$ pada bilangan gelombang $1265,30 \mathrm{~cm}^{-1}$, sedangkan identifikasi dengan ${ }^{1} \mathrm{H}-\mathrm{NMR}$ diketahui bahwa senyawa mempunyai puncak singlet pada $\delta=6$ ppm merupakan proton dari $\mathrm{CH}_{2}$, puncak multiplet pada $\delta=6,9-7,7$ ppm dari proton dua cincin aromatik dan puncak singlet pada $\delta=8,4$ ppm dari proton imina. Nilai KHM produk sintesis turunan imina terhadap bakteri Staphylococcus aureus dan Escherichia coli adalah pada konsentrasi $1 \mathrm{mg} / \mathrm{mL}$ dengan diameter zona hambat masing-masing adalah $2 \mathrm{~mm}$ dan $3 \mathrm{~mm}$. Dari data tersebut dapat disimpulkan bahwa produk sintesis turunan imina 3,4-metilendioksibenzilimina telah terbentuk dan mempunyai kemampuan sebagai antibakteri. 


\section{Pendahuluan}

Penyakit infeksi merupakan salah satu masalah dalam bidang kesehatan yang dari waktu ke waktu terus berkembang, disebabkan oleh berbagai mikroorganisme seperti bakteri, virus, jamur, dan protozoa [1]. Imina merupakan senyawa dengan gugus fungsi $\mathrm{C}=\mathrm{N}$ yang mempunyai potensi sebagai antibakteri [2], antikanker [3], antijamur, antitumor dan antimalaria [4]. Sintesis turunan imina dari vanilin dan 4-aminoantipirin yang mempunyai aktivitas sebagai antibakteri. Melihat potensinya yang besar, maka penelitian tentang imina perlu dikembangkan, sehingga dapat mempunyai aktivitas yang tinggi dan lebih stabil [5].

Schmeyers $d k k$. [6],telah melakukan penelitian sintesis imina, dimana reaksi dilakukan pada suhu kamar selama 30 menit. Hania [7] berhasil mensintesis senyawa imina menggunakan bahan dasar anilin dan benzaldehid, reaksi dilakukan dengan pemanasan selama dua jam dan dihasilkan produk dengan titik leleh 50-52 ${ }^{\circ} \mathrm{C}$ dan randemen $60 \%$. Secara umum, imina merupakan hasil reaksi kondensasi antara aldehida dan amina. Aldehid aromatik seperti piperonal dengan amina primer akan menghasilkan imina yang stabil [8], karena akan menghasilkan produk dengan cincin aromatik dan ikatan rangkap yang terkonjugasi. Konsep reaksi tersebut dapat digunakan untuk sintesis imina dari piperonal dan anilin.

Piperonal merupakan suatu aldehida aromatik tanpa $\mathrm{H} \alpha$ yang memiliki kemiripan struktur dengan benzaldehid. Sedangkan anilin merupakan amina primer yang merupakan suatu nukleofil yang dapat menyerang gugus karbonil suatu aldehid atau keton, sehingga pada penelitian dapat digunakan sebagai alternatif pembuatan senyawa turunan imina. Piperonal mempunyai gugus metilendioksi $\left(-\mathrm{O}-\mathrm{CH}_{2}-\mathrm{O}-\right)$, dimana menurut Alam [9] senyawa yang mengikat gugus metilendioksi(-O- $\left.\mathrm{CH}_{2}-\mathrm{O}-\right)$ berpotensi mampu meningkatkan aktivitas antibakteri.

Reaksi imina (imina) dipengaruhi oleh beberapa faktor, antara lain suhu, $\mathrm{pH}$, dan waktu reaksi yang digunakan. Salah satu keberhasilan reaksi imina adalah waktu reaksi. Dalam penelitian ini dilakukan variasi waktu reaksi yang digunakan. Berdasarkan uraian tersebut, untuk menghasilkan produk sintesis imina yang optimal perlu ditentukan waktu reaksi, sehingga memperoleh randemen yang optimal dan mempunyai kemampuan sebagai antibakteri.

\section{Metode Penelitian}

\section{Alat dan Bahan}

Alat yang digunakan adalah seperangkat alat gelas untuk sintesis, lempeng KLT silika gel, spectronic 20, seperangkat alat untuk uji antibakteri, LCMS (liquid chromatography mass spectroscopy), spektrometer FTIR (Shimadzu) dan spektrometer ${ }^{1} \mathrm{H}-\mathrm{NMR}$. Bahan yang dipergunakan adalah anilina p.a., piperonal p.a., etanol $96 \%$, asam klorida, kloroform, magnesium sufat anhidrat, tween 20 , sepernagkat bahan uji antibakteri, bakteri Staphylococcus aureus dan Escherihia coli.
Pengaruh waktu reaksi sintesis turunan imina dari piperonal dan anilin.

Piperonal 3,006 g (0,02 mol) dilarutkan dalam 20 $\mathrm{mL}$ etanol. Pelarutan dilakukan dalam labu leher tiga volume $250 \mathrm{~mL}$ yang dilengkapi dengan pendingin, pengaduk magnetik dan termometer. Setelah piperonal larut, ditambahkan 0,03 mol larutan anilin berlebih sampai larutan homogen kemudian ditambahkan $\mathrm{HCl} 1$ M. Reaksi dilakukan pada suhu kamar dengan variasi waktu 50, 70, 90, 110, 130 dan 150 menit. Campuran kemudian diekstraksi, fraksi yang terbentuk dipisahkan dan dikeringkan.filtratnya diuapkan dengan rotary evaporator. Kemudian hasil yang terbentuk dikeringkan dan diukur titik lelehnya. Analisis dengan LC-MS, spektroskopi FTIR dan ${ }^{1} \mathrm{H}-\mathrm{NMR}$.

\section{Pembuatan suspensi bakteri}

Pembuatan stok bakteri, bakteri uji dibiakkan pada media cair selama 24 jam pada suhu $35-37^{\circ} \mathrm{C}$, kemudian diambil dengan ose dan disuspensikan dengan cara memasukkan kedalam $10 \mathrm{~mL}$ air suling steril. Suspensi yang terbentuk disetarakan pada transmitans $25 \%$ dengan panjang gelombang $580 \mathrm{~nm}$.

\section{Pengujian antibakteri}

Sebanyak 0,1 mL inokulum bakteri dimasukkan kedalam cawan petri steril, setelah itu dituang media Nutrient Agar ebanyak $20 \mathrm{~mL}$ dangan suhu $40-50^{\circ} \mathrm{C}$. Selanjutnya cawan digoyang diatas permukaan meja, agar media dan suspensi tercampur rata. Cakram kertas berdiameter $6 \mathrm{~mm}$ dicelupkan ke dalam produk sintesis dengan konsentrasi $100 \mathrm{mg} / \mathrm{mL}, 50 \mathrm{mg} / \mathrm{mL}, 10 \mathrm{mg} / \mathrm{mL}$, $5 \mathrm{mg} / \mathrm{mL}, 1 \mathrm{mg} / \mathrm{mL}$ dan $0,5 \mathrm{mg} / \mathrm{mL}$. Kontrol yang di gunakan tween-20 55mg/mL (kontrol negatif) dan tetrasiklin $0,1 \mathrm{mg} / \mathrm{mL}$ (kontrol positif) dibiarkan 15 menit. Cakram kertas diletakkan diatas permukaan media agar yang telah diinokulasikan dengan suspensi bakteri, kemudian diinkubasidalam inkubator pada suhu $36 \pm 1^{\circ} \mathrm{C}$ selama $18-24$ jam, setelah itu diukur diamterer daerah hambatan (zona jernih) pertumbuhan disekitar cakram kertas

\section{Hasil dan Pembahasan}

Pada penelitian ini, perlu dilakukan uji kemurnian turunan imina sebagai starting material yang dilihat deri pengukuran profil KLT. harga Rf ditunjukkan pada tabel 1.

Tabel 1 : Harga Rf senyawa turunan imina

\begin{tabular}{ccc}
\hline No & Jenis pelarut & Rf sintesis imina \\
\hline 1 & Kloroform & 0,62 \\
2 & benzena & 0,48 \\
\hline
\end{tabular}

Dari hasil uji kemrurnian senyawa turunan imina, dapat disimpulkan bahwa senyawa turunan imina cukup murni.

Dalam penelitian ini, senyawa turunan imina ini disintesis melalui reaksi kondensasi antara piperonal dan aniline dengan reaksi adisi dan eliminasi. Dalam sintesis ini menggunakan katalis asam, yaitu $\mathrm{HCl}$, 
karena reaksi pembentukan imina dipengaruhi oleh kondisi pH 3-4. Apabila pH terlalu asam akan mempengaruhi tahap eliminasi berjalan lebih cepat sedangkan apabila $\mathrm{pH}$ kurang asam tahap eliminasi menjadi lambat karena konsentrasi asam mempengaruhi protonasi gugus $\mathrm{OH}$. Sehingga akan mempengaruhi turunan imina yang dihasilkan. Sintesis ini dilakukan pada suhu kamar dengan variasi waktu reaksi seperti pada tabel 2.

Pengaruh waktu reaksi terhadap produk sintesis (tabel 2) menunjukkan bahwa waktu optimal terjadi pada waktu reaksi 130 menit dengan randemen sebesar $62,53 \%$. Pada waktu reaksi di bawah 130 menit imina belum memberikan hasil yang maksimal, karena reaksi belum berlangsung secara sempurna. Sedangkan pada waktu reaksi setelah 130 menit terjadi penurunan produk sintesis. Fenomena ini disebabkan imina yang telah terbentuk dapat bereaksi kembali, dengan terjadinya protonasi oleh $\mathrm{H}^{+}$, sehingga menghasilkan karbon parsial positif yang dapat diserang oleh nukleofil yang ada dalam campuran produknya, antara lain ion $(\mathrm{OH})^{-}$, air dan sisa anilin, sehingga akan mengurangi produk yang dihasilkan [8].

Tabel 2: Pengaruh waktu reaksi terhadap produk sintesis

\begin{tabular}{ccccc}
\hline No & $\begin{array}{c}\text { Waktu } \\
\text { reaksi } \\
(\text { menit })\end{array}$ & $\begin{array}{c}\text { Titik } \\
\text { leleh } \\
\left({ }^{\circ} \mathrm{C}\right)\end{array}$ & $\begin{array}{c}\text { Produk } \\
(\text { gram })\end{array}$ & $\begin{array}{c}\text { Randemen } \\
(\%)\end{array}$ \\
\hline 1 & 50 & 60 & 1,310 & 29,07 \\
2 & 70 & 60 & 1,371 & 30,43 \\
3 & 90 & 61 & 2,596 & 57,62 \\
4 & 110 & 56 & 2,778 & 61,88 \\
5 & 130 & 59 & 2,817 & 62,53 \\
6 & 150 & 59 & 2,396 & 53,18 \\
\hline
\end{tabular}

Hasil Spektra FTIR

Spektra FTIR dari piperonal ditunjukkan pada gambar 1 dan hasil spektra FTIR dari turunan imina ditunjukkan pada gambar 2 .

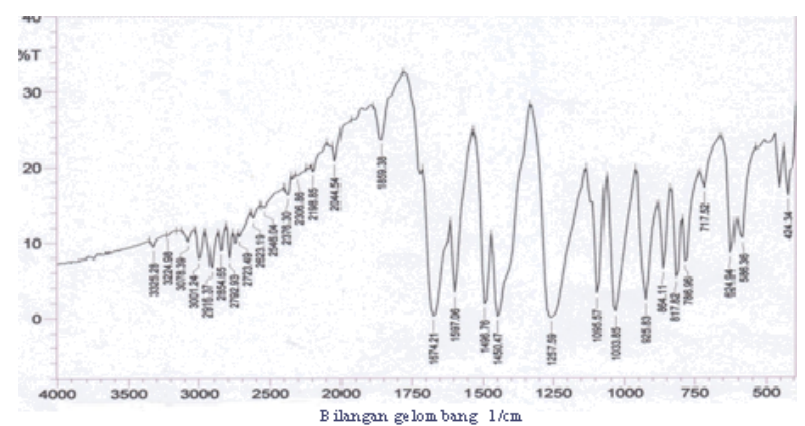

Gambar 1. FTIR Piperonal

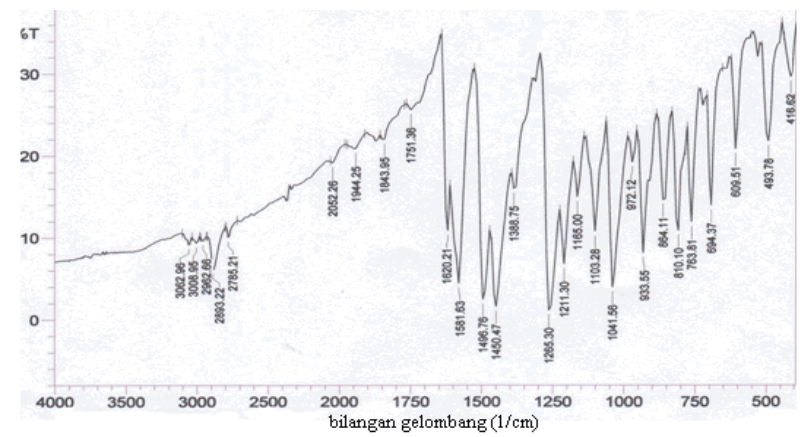

Gambar 2. FTIR 3,4-metilendioksibenzilimina

Tabel 3 : Data FTIR antara piperonal dan produk hasil sintesis

\begin{tabular}{cccc}
\hline \multirow{2}{*}{ No } & Gugus & \multicolumn{2}{c}{ Bilangan gelombang $\left(\mathrm{cm}^{-1}\right)$} \\
\cline { 3 - 4 } & & Piperonal & Produk sintesis \\
\hline 1 & C=O aldehid & 1674,$21 ;$ & - \\
& & 2792,$93 ;$ & \\
& & 2854,65 & \\
2 & imina & - & 1620,$21 ;$ \\
& & & 2893,22 \\
3 & C-H aromatik & 1597,06 & 1581,63 \\
& & 786,$86 ;$ & 694,$37 ;$ \\
& & 817,$2 ;$ & 763,$81 ;$ \\
& & 864,11 & 810,$10 ;$ \\
4 & & & 884,11 \\
5 & $\mathrm{C}_{(\mathrm{sp} 3)}-\mathrm{H}\left(\mathrm{CH}_{2}\right)$ & 2916,$37 ;$ & 2962,$37 ;$ \\
& & 1450,47 & 1450,47 \\
6 & $\mathrm{C}_{(\mathrm{sp} 2)}-\mathrm{H}$ & 3078,39 & 3062,96 \\
\hline
\end{tabular}

Berdasarkan data spektra FTIR tersebut, terjadi perbedaan serapan yang dihasilkan sebelum maupun sesudah reaksi, dimana sebelum reaksi terdapat gugus karbonil $(\mathrm{C}=\mathrm{O})$ sedangkan sesudah reaksi terdapat penambahan gugus imina $(\mathrm{C}=\mathrm{N})$ dan pengurangan gugus karbonil $(\mathrm{C}=\mathrm{O})$ pada produk sintesis. Dengan adanya gugus-gugus tersebut, berarti senyawa imina yang diharapkan telah terbentuk.

\section{Hasil Spektra ${ }^{1} \mathrm{H}-\mathrm{NMR}$}

Karakterisasi menggunakan spektroskopi ${ }^{1} \mathrm{H}-\mathrm{NMR}$. Pengujian menggunakan ${ }^{1} \mathrm{H}-\mathrm{NMR}$ dilakukan untuk mengetahui jumlah proton yang dimiliki oleh senyawa produk sintesis berdasarkan lingkungan elektroniknya. Hasil ${ }^{1} \mathrm{H}-\mathrm{NMR}$ ditunjukkan pada gambar 3 dan tabel 4 .

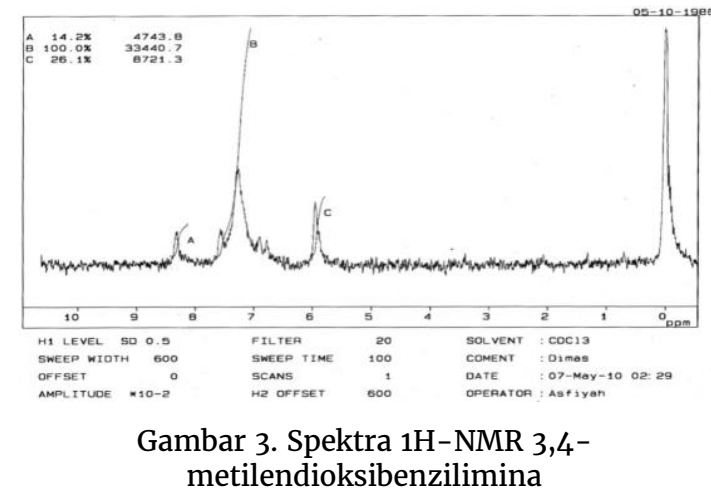


Spektra $\quad{ }^{1} \mathrm{H}$-NMR $\quad$ 3,4-metilendioksibenzilimina terlihat bahwa senyawa hasil sintesis yang diperoleh menunjukkan tiga buah signal yang terpisah. Hal ini disebabkan adanya tiga proton yang memiliki tiga lingkungan elektronik yang berbeda dengan perbandingan proton 1:8:2. Perbandingan ini diinterprestasikan sebagai perbandingan jumlah proton yang terdapat dalam senyawa hasil sintesis. Adanya puncak multiplet pada $\delta=6,9-7,7$ ppm merupakan ciri khas dari proton hidrogen aromatik. Munculnya puncak singlet sekitar $\delta=8,4 \mathrm{ppm}$ merupakan proton yang berasal dari gugus imina $(1 \mathrm{H},-\mathrm{CH}=\mathrm{N})$ sedangkan adanya puncak singlet pada $\delta=6 \mathrm{ppm}$ merupakan proton dari gugus metilen $\left(\mathrm{CH}_{2}\right)$. Data ${ }^{1} \mathrm{H}-\mathrm{NMR}$ 3,4metilendioksibenzilimina dapat dilihat pada tabel 4 .

Tabel 4: Data ${ }^{1} \mathrm{H}$-NMR 3,4-metilendioksibenzilimina

\begin{tabular}{|c|c|c|c|}
\hline No & Sinyal & $\begin{array}{c}\text { Pergeseran } \\
\text { Kimia } \delta(\mathrm{ppm})\end{array}$ & $\begin{array}{l}\text { Jumlah dan } \\
\text { Kedudukan } \\
\text { atom H }\end{array}$ \\
\hline $\mathrm{A}$ & Singlet & 8,4 & $1 \mathrm{H}$ dari $\mathrm{CH}=\mathrm{N}$ \\
\hline B & Multiplet & $6,9-7,7$ & $\begin{array}{l}8 \mathrm{H} \text { dari } \mathrm{C}-\mathrm{H} \\
\text { aromatik }\end{array}$ \\
\hline $\mathrm{C}$ & Singlet & 6 & $2 \mathrm{H}$ dari $\mathrm{CH}_{2}$ \\
\hline
\end{tabular}

Kromatogram dan spektrogram turunan imina ditunjukkan pada gambar 4.

Kromatogram (A) menunjukkan adanya 2 puncak dengan waktu retensi $\left(\mathrm{R}_{\mathrm{t}}\right)$ dan luas puncak (\%) berturut-turut: puncak 1, $\mathrm{R}_{\mathrm{t}}$ 1,05 menit (3\%) dan puncak $2, t_{R}$ 2,22 menit (97\%), berarti senyawa hasil sintesis tersebut dapat dianggap telah murni. Spektra massa (B) yang diperoleh memperlihatkan adanya berat molekul pada $\mathrm{m} / \mathrm{z} 226.30[\mathrm{M}+\mathrm{H}]^{+}$, yang merupakan puncak dengan intensitas tertinggi (97\%). Berarti berat molekul senyawa hasil sintesis adalah $226,30-1=225,30$ mengindikasikan berat molekul $\mathrm{m} / \mathrm{z} 225,30\left[\mathrm{M}^{+}\right]$yang identik dengan struktur 3,4-metilendioksibenzilimina $\left(\mathrm{C}_{14} \mathrm{H}_{11} \mathrm{O}_{2} \mathrm{~N}\right)$ seperti pada gambar 5 .

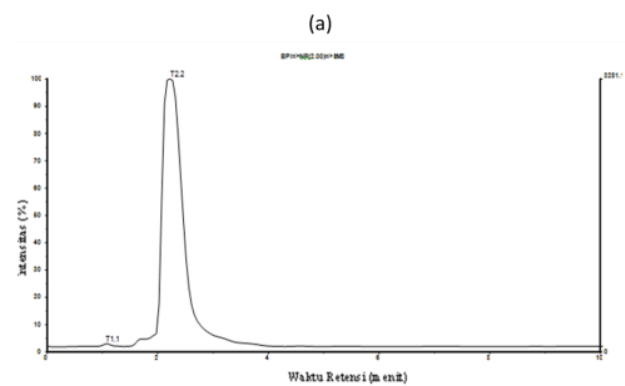

(b)

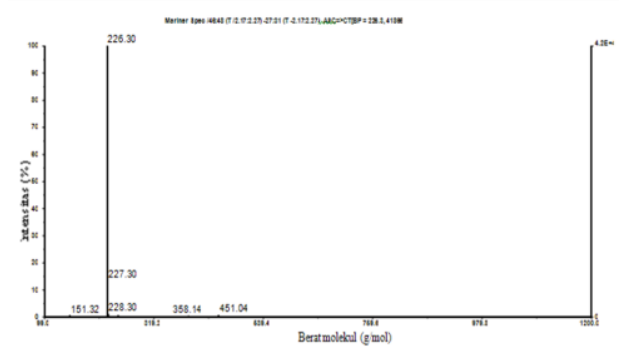

Gambar 4. Kromatogram (A) dan spektrogram (B) 3,4metilendioksibenzilimina

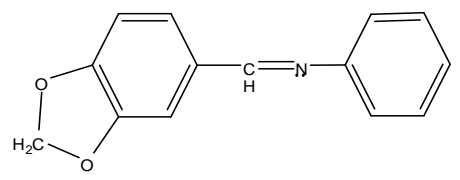

Gambar 5. 3,4-metilendioksibenzilimina

Hasil Uji Antibakteri

Tabel 5: Hasil Uji Aktivitas Antibakteri

\begin{tabular}{cccc}
\hline & Konsentrasi & \multicolumn{2}{c}{ Diameter Hambat (mm) } \\
\cline { 3 - 4 }$(\mathrm{mg} / \mathrm{mL})$ & $\begin{array}{c}\text { Staphylococcus } \\
\text { aureus }\end{array}$ & $\begin{array}{c}\text { Escherichia } \\
\text { coli }\end{array}$ \\
\hline 1 & 100 & 11,67 & 12,67 \\
2 & 50 & 9,67 & 10,67 \\
3 & 10 & 6 & 7,33 \\
4 & 5 & 3 & 3,67 \\
5 & 1 & 2 & 3 \\
6 & 0,5 & - & - \\
7 & Tetrasiklin 0,1 & 10,33 & 10,67 \\
8 & kontrol negatif & - & - \\
\hline
\end{tabular}

Keterangan:

$(-)$

: tidak memberikan hambatan

Kontrol positif $\quad$ : tetrasiklin $0,1 \mathrm{mg} / \mathrm{ml}$

Kontrol negatif : tween-20 $55 \mathrm{mg} / \mathrm{m}$

Hasil uji antibakteri turunan senyawa imina terhadap bakteri Staphylococcus aureus dan Escherichia coli ditunjukkan pada tabel 5. Pada Tabel 5, terlihat bahwa produk sintesis turunan imina memberikan batas daerah hambatan dengan diameter $2 \mathrm{~mm}$ pada konsentrasi $1 \mathrm{mg} / \mathrm{mL}$ untuk bakteri Staphylococcus aureus dan diameter $3 \mathrm{~mm}$ pada konsentrasi $1 \mathrm{mg} / \mathrm{mL}$ pada konsentrasi $1 \mathrm{mg} / \mathrm{mL}$ untuk bakteri Escherichia coli. Dari tabel diatas terlihat bahwa diameter zona hambat semakin meningkat seiring dengan peningkatan $\begin{array}{lll}\text { konsentrasi produk sintesis } & 3,4\end{array}$ metilendioksibenzilimina, sehingga dapat diketahui Konsentrasi Hambat Minimum (KHM). Hasil uji antibakteri menunjukkan bahwa Produk sintesis 3,4metilendioksibenzilimina memiliki KHM pada konsentrasi $1 \mathrm{mg} / \mathrm{mL}$ terhadap bakteri Staphylococcus aureus dan Escherichia coli.

\section{Kesimpulan}

Senyawa turunan imina dari piperonal dan anilin dapat disintesis melalui reaksi imina dan pengaruh waktu reaksi selama 130 menit menghasilkan produk optimal yaitu $62,53 \%$. Senyawa turunan imina mempunyai aktivitas sebagai antibakteri terhadap bakteri Staphylococcus aureus dan Eschericia coli.

\section{Daftar Pustaka}

[1] JM Gibson, Mikrobiologi dan Patologi Modern untuk perawat, Terjemahan dan Modern Microbiology and Pathologi for Nurses, oleh Soma Prasada. EGC, Jakarta, (1996) 
[2] Neeraj Kumar Fuloria, Vijender Singh, M. Shaharyar, Mohammed Ali, Synthesis, characterization and antimicrobial evaluation of novel imines and thiazolidinones, Acta Poloniae Pharmaceutica \& Drug Research, 66, 1, (2009) 141146

[3] Amjid Iqbal, Hamid Latif Siddiqui, CM Ashraf, Matloob Ahmad, George W Weaver, Synthesis, Characterization and Antibacterial Activity of Azomethine Derivatives Derived from 2Formylphenoxyacetic Acid, Molecules, 12, 2, (2007) 245-254 http://dx.doi.org/10.3390/12020245

[4] Sandra S Konstantinović, Budimir V Konstantinović, Jasmina M Jovanović, Synthesis and structure of vanillin azomethines, Chemical Industry and Chemical Engineering Quarterly/CICEQ 15, 4, (2009) http://dx.doi.org/10.2298/CICEQ0904279K

[5] B Soekardjo, S Hardjono, R Sondakh, Hubungan struktur-aktivitas obat antibiotika. Dalam: Siswandono \& Soekardjo. B, Kimia Medisinal, 2, (2000)

[6] Jens Schmeyers, Fumio Toda, Juergen Boy, Gerd Kaupp, Quantitative solid-solid synthesis of azomethines, Journal of the Chemical Society, Perkin Transactions 2, 4, (1998) 989-994

[7] Majed M Hania, Synthesis of some imines and investigation of their biological activity, Journal of Chemistry, 6, 3, (2009) 629-632

[8] RJ Fessenden, JS Fessenden, Kimia Organik, diterjemahkan oleh Pudjaatmaka, AH, jilid, 1, (1994) 209-210

[9] Sayed Alam, Synthesis, antibacterial and antifungal activity of some derivatives of 2-phenyl-chromen4-one, Journal of Chemical Sciences, 116, 6, (2004) 325-331 